\title{
Heroin Maintenance Treatment - Are the Further Investigation Needed?
}

\author{
Tatjana Petrushevska \\ Ministry of Health of the Republic of Macedonia, Skopje, Republic of Macedonia
}

\begin{abstract}
Citation: Petrushevska T. Heroin Maintenance Treatment - Are the Further Investigation Needed? Maced J Med Sci. 2012 Dec 15; 5(4):453-461. http://dx doi org/10.3889/MJMS.18575773.2012.0238.

Key words: Heron maintenance; drug dependence; diacetylmorphine; dose of heroin.

Correspondence: Tatjana Petrushevska Pharm.Spec.MBA. Currently Doctoral student on Basic Medicine, Faculty of Medicine, University "Sv.Kiril and Metodij", Skopje, Republic of Macedonia Address: "50 Divizija" No 6, 1000 Skopje Republic of "So Diviza" No 6, 1000 Skopje, Republic of Macedonia. Tel. +38923112 435. E-mail: tanja.petrusevska@gmail.com

Received: 29-Mar-2012; Revised: 20-Oct-2012 Accepted: 25-Oct-2012; Online first: 01-Nov-2012

Copyright: (c) 2012 Petrushevska T. This is an open-access article distributed under the terms of the Creative Commons Attribution License, permits unrestricted use, distributio, which permits unrestricted use, distribution, and reproduction in any medium, provided the origina author and source are credited.

Competing Interests: The author have declared
\end{abstract} that no competing interests exist.

\begin{abstract}
The aim of this review is to give new emphasis to key aspects of the proposed treatment of drug addiction. Surveys for so called "second-line" treatment of drug addiction, with heroin (diacetylmorphine) as a pharmaceutical preparation, started since 1990 , but this issue is becoming particularly popular in the last period. Drug addiction according to WHO and International Classification of Diseases (ICD10) is chronic, relapsing disease characterized by compulsive drug seeking and use despite harmful consequences as well as neurochemical and molecular changes in the brain. Drugs generate crime, violence and other social problems that are damaging society as a whole. Drug addiction is medical disorder to which contributes more factors and it is necessary to implement the treatment in multi disciplinary manner - from pharmacological, psychiatric, and social aspect. In recent periods studies are carrying out in several countries in the European region, to provide justification, with the scientific medical evidence, for use of heroin as a pharmaceutical dosage form, for treatment of drug addictions for previously unresponsive group. This review paper is focused on maintenance treatment with heroin, retention of the patients into treatment, whether the dose that is expected to be effective at the same time is safe, which organ (systems) are involved in eliminating the drug from the body, whether the injection is the best way for application of the drug.
\end{abstract}

Purpose of this review paper is not to be supporter or opponent, but to inform, transparently to discuss all aspects and to set conclusions about this type of treatment, within national strategy context.

\section{Introduction}

Drug addicts are characterized by persistence in the use of drugs, often combined use of several types of drugs in the same period (F19 - Poly Drug Use), and regardless of the difficulties faced in terms of impaired health, problems related to law, social issues, problems in the family and global functioning in society, criminal behavior and disturbance of the public order, nuisance, under the influence of drugs [1].

Health problems faced by drug addicts are associated with weaken functioning of major organs liver, renal, pulmonary diseases, cardiovascular diseases, fertility etc. The exchange of non-sterile needles and syringes among drug addicts who inject, gives a possibility for transmission of blood-transmitted diseases such as hepatitis, HIV / AIDS, but also occurrence of 
abscesses, infections, damage of veins, thrombosis of the veins, septicemia (generalized bacterial infection of the blood), endocarditic, pulmonary embolism. Many theories explained why individuals with severe mental illnesses are vulnerable to the misuse of substances and how the mental illness-substance misuse relationship co-exists. Does having a psychotic illness lead to substance misuse and in what way? Or is it the case that substance misuse causes psychotic illness? [2].

Opioid dependence is characterized by a range of cognitive, behavioral and psychological disorders [3]. Person needs a drug to function normally. The principles of treatment of drug addiction in accordance with World Health Organization, includes availability and affordability of treatment of disease with pharmacological therapy that has proven effectiveness and efficiency in stabilizing the person with developed drug addiction, based on scientific evidence. The treatment should incorporate psychological and social interventions. Also, the principles of treatment understands reducing of comorbidity, decreasing the risk of mortality associated with use of drugs to a greater extent possible, increasing physical, mental and social capabilities of the person, resocialization and social integration in society. No single treatment is effective and fits to all individuals. Patients on treatment for opioid dependence have different patterns of use of drugs, different psychological and social problems and diverse risk and protective factors that lead to dependence. That is the reason why treatment should be balanced combination of pharmacotherapy, psychotherapy, psychosocial rehabilitation and reduction of risk factors. Today in global context, there are a number of possibilities for the treatment of people who have developed a drug addiction. Treatment is delivered in outpatient, inpatient, and residential settings. Although specific treatment approaches often are associated with particular treatment settings, a variety of therapeutic interventions or services can be included in any given setting [45]. There are various interventions: detoxification, counseling, maintenance therapy with pharmacological substitution medicine, group work, individual treatment. But all of them have the same goal, to stabilize the patient after some period of abstinance from using narcotic and then maintain this conditions, avoid relapse. Significant therapeutic efforts should be focus on keeping the patient drug-free. National Institute on Drug Abuse of the USA (NIDA) defines addiction as a chronic, relapsing disease characterized by compulsive drug seeking and use despite harmful consequences as well as neurochemical and molecular changes in the brain [46]. Due to developed physical and psychological dependence, it is difficult to achieve abstinence, especially in a short period of time. Therefore as a substitute to drugs taken from the street, with unsure quality, purity, numerous possible side effects of added substance with aim to increase the volume in correlation with decreasing of the concentration of active component, two approaches for treatment, which can be option of choice of the patient, are developed. One is a detoxification and other treatment with maintenance opioid. Pharmacological treatment of drug addicted person can be with: opioid agonist, partial agonist, opioid antagonist, alpha-2adrenergic agonists. Detoxification is still with limited time efficiency.

Methadone is a full mu-opioid receptor agonist, typically used as a replacement therapy for heroin or other opioid dependence. Methadone's slow start of action when taken orally and long elimination half-life (24-36 hours), allows it to be used as either as a maintenance therapy or detoxification agent [4]. WHO recommendation is that methadone maintenance doses should be in the range of 60-120 mg per day [5].

Methadone maintenance treatment is associated with retention in treatment, and reductions in drug use, criminal activity, and HIV risk behaviors and mortality [69]. It is currently the most successful treatment for chronic opioid dependence [10].

Around three-quarters of people who enter methadone substitution treatment respond well [52] [53]. On the other hand, for various reasons, methadone does not go well with all opioid-dependent people. For this group it is important that alternative approaches are available to encourage their retention in treatment. International trials suggest that the supervised use of medicinal heroin can be an effective second-line treatment for this small, and previously unresponsive, group. In practice, most patients who beginning opioid agonist treatment will stop using heroin or use it occasionally, with only 20-30\% reporting ongoing regular heroin use $[16,17]$.

Heroin is semi synthetic derivate. It can be produced with process of acetylating of the natural alkaloid morphine, which is extracted from certain varieties of the plant Papaver somniferum. In the past, extraction of morphine and other alkaloids take place by incision of the poppy straw, in a certain time of the year when it reaches the desired maturity of the plant, and thus the accumulation of alkaloids. From the cut parts of the poppy straw, leakage juice which under the influence of external temperature, condense. This juice (latex) 
represents the concentration of alkaloids; it is collected and is known as opium. This procedure when alkaloids are obtaining for medical purposes is now prohibited by international legal acts [11], but still admitted to illegal acts, since it provides the highest concentration of active components. For medical purposes, poppy are harvesting in the upper part of the plant and is treated with chemicals to extract alkaloids - the active components, and then evaporating the used chemicals, using known techniques for pharmaceutical synthesis. The largest producer of illicit opium and heroin is Afghanistan in a worldwide scale [13]. According to UNODC it is estimated 12-14 million heroin users in the world, using around $375 \mathrm{mt}$ (metric tons) of heroin [13]. Europe is one of the most important markets for heroin with an estimated $250 \mathrm{~kg}$ of heroin used per day [14]. Heroin was first synthesized at St Mary's hospital in London in 1874. In 1898, it was produced as a new drug by pharmaceutical company Bayer. Heroin was initially introduced into the medical world as a respiratory stimulant (particularly for tuberculosis), however later it was found to be a respiratory depressant. It was also widely used as an analgesic. Consequently, it was suggested that it might be an effective cure for morphine addiction but it was soon found itself to have addictive properties. It was found that this product is 2 to 3 times more powerful than morphine, because of its great liposolubility, which allows quickly passing the barriers and entering the central nervous system. That is the reason why it was given the protected trade name "heroin", precisely because of the great, heroic power which is mostly used in the treatment of tuberculosis, for suppression of coughing. But, patients suffering from tuberculosis continued to die, which confirms that this product only stopped the pain and worked to suppress cough but not cure the disease. Heroin was used to combat opium dependence, but soon after introduction into treatment it was confirmed that heroin causes greater dependence than that of morphine [14]. Heroin is a strong analgesic and is highly effective in the treatment of pain. It is mainly injected.

Renewal of use of heroin as a medicine, now for treatment of drug dependence may have benefits, as well as risks. This issue requires looking in depth in the research evidence to determine whether heroin has advantages over other treatment options for some conditions.

\section{Materials and Methods}

This review paper was produced after comprehensive systematic review of international literature on evidence of effectiveness of treatment of drug dependence, search for relevant articles in: medical Journal, reports, info facts and literature search in NIDA, SAMSHA, EMCDDA, WHO, UNAIDS, UNODC.

Electronic search for the existing data was carried out in: in databases (Medline/Pub Med, Cochrane Central Register of Controlled Trials (CENTRAL), Elsevier, Google scholar, Medical Subject Headings, DocGuide, , Psycinfo), in publications, monographs, standards and guidelines.

Search terms which were used are: pharmaceutical heroin, diacetylmorphine, maintenance program with heroin, supervised use of heroin, pharmacological profile of heroin.

\section{Results}

In this part of the paper are presented description of the reviewed studies, scientific evidence for injectible treatment with heroin, under supervision of health professional, that was accumulate through international trials.

To date, multisite, prospective, open labeled, randomized, control trials were conducted in six countries Switzerland, Germany, Holland, England, Spain, Canada. Target groups were chronic heroin dependent individuals, severe, treatment-resistant heroin addicts, selected by random selection, and were aged 18 to 65 . Trials were conducted for treatment with heroin under supervision, reached 1500 patients [18]. The duration of the tests varies between countries from 6 to 12 months. Positive aspects of the conducted tests are that they were applied in the principles of Good Medicine and Good Clinical Practice according to WHO, ICH / EU standards. Also, studies were conducted under the provisions of the Declaration of Helsinki and Medical Ethics Manual regarding the ethical aspects of studies, obtaining consent from patients after their informing in detail about the study, expected outcomes of the study, possible risks and concerning the protection of personal data.

Trials were conducted in accordance with developed protocols [19] in compliance with the international guidelines for Good Clinical Practice. One type of protocol was for the investigation of the effectiveness of intravenously injected heroin and another protocol for the trial involving inhaled heroin [20].

Main goals of the scientific trials were: treatment 
Table 1: Design and results of the reviewed studies.

\begin{tabular}{|c|c|c|c|c|c|c|c|c|c|c|c|c|c|c|c|}
\hline \multirow{3}{*}{ Country } & \multicolumn{2}{|c|}{$\begin{array}{l}\text { Sample } \\
\text { size }\end{array}$} & \multicolumn{3}{|c|}{$\begin{array}{l}\text { Way of } \\
\text { application }\end{array}$} & \multirow{3}{*}{$\begin{array}{l}\text { Time } \\
\text { months }\end{array}$} & $\begin{array}{l}\text { Dose of the } \\
\text { Heroin group } \\
\text { (mean) Heroin } \\
+ \text { flexible }\end{array}$ & $\begin{array}{l}\text { Dose } \\
\text { Methad. } \\
\text { group }\end{array}$ & \multicolumn{7}{|c|}{ RESULTS } \\
\hline & \multirow[b]{2}{*}{ 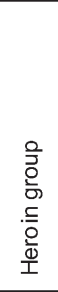 } & \multirow{2}{*}{ 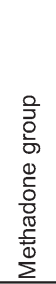 } & \multicolumn{2}{|c|}{ Heroin } & \multirow{2}{*}{ 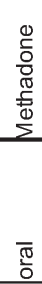 } & & \multirow[t]{2}{*}{ Heroin } & \multirow[t]{2}{*}{ Methadone } & \multicolumn{2}{|c|}{$\begin{array}{l}\text { Retention in } \\
\text { treatment }\end{array}$} & \multicolumn{2}{|c|}{$\begin{array}{l}\text { Self reported } \\
\text { illicit heroin } \\
\text { use }\end{array}$} & \multicolumn{2}{|c|}{$\begin{array}{l}\text { Improvement } \\
\text { (Physical, Social, } \\
\text { Psychiatric health } \\
\text { response to } \\
\text { treatment }\end{array}$} & \multirow[t]{2}{*}{$\begin{array}{l}\text { Serious } \\
\text { Adverse } \\
\text { events }\end{array}$} \\
\hline & & & 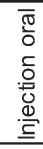 & 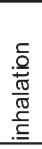 & & & & & $\begin{array}{l}\text { 등 윽 } \\
\text { 온 옹 }\end{array}$ & 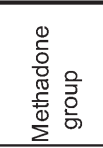 & 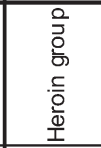 & 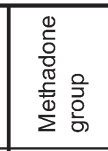 & 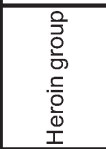 & 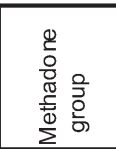 & \\
\hline Switze rland & 27 & 24 & $x$ & & $x$ & 6 & $509 \mathrm{mg}$ & & $\begin{array}{l}93 \% \\
25 \\
\text { persons }\end{array}$ & $\begin{array}{l}92 \% \\
22 \\
\text { persons }\end{array}$ & \begin{tabular}{|l|}
$22 \%$ \\
6 \\
ber sons
\end{tabular} & \begin{tabular}{|l}
$67 \%$ \\
16 \\
persons
\end{tabular} & & & $\mathrm{N} / \mathrm{A}$ \\
\hline \multirow{3}{*}{ Netherlands } & 76 & 98 & $x$ & & & 12 & $548 \mathrm{mg}$ & $60 \mathrm{mg}$ & $\begin{array}{l}72 \% \\
55 \text { pers. }\end{array}$ & $\begin{array}{l}85 \% \\
83 \text { pers. }\end{array}$ & \multicolumn{2}{|c|}{$\begin{array}{l}25 \text { days in the } \\
\text { last month }\end{array}$} & $56 \%$ & $31 \%$ & 9 \\
\hline & 117 & 139 & & $x$ & $x$ & 12 & $\begin{array}{c}548 \mathrm{mg} \text { (max of } \\
1000 \mathrm{mg} \text { per } \\
\text { day } / 400 \mathrm{mg} \text { per } \\
\text { visit) }\end{array}$ & $60 \mathrm{mg}$ & $\begin{array}{l}68 \% \\
80 \text { pers. }\end{array}$ & $\begin{array}{l}87 \% \\
121 \\
\text { pers. }\end{array}$ & \multicolumn{2}{|c|}{$\begin{array}{l}26 \text { days in the } \\
\text { last month }\end{array}$} & $40 \%$ & & 14 \\
\hline & 75 & 23 & & $x$ & $x$ & 6 & $\begin{array}{c}502 \mathrm{mg} \\
\text { Averaged }\end{array}$ & $60 \mathrm{mg}$ & $44,5 \%$ & & \multicolumn{2}{|c|}{$\begin{array}{l}25 \text { days in the } \\
\text { last month }\end{array}$} & & & 12 \\
\hline Spain & 31 & 31 & $x$ & & $x$ & 9 & $275 \mathrm{mg}$ & $105 \mathrm{mg}$ & $\begin{array}{l}74 \% \\
23 \text { pers. }\end{array}$ & $\begin{array}{l}68 \% \\
21 \text { pers. }\end{array}$ & $\begin{array}{l}8.3 \% \\
3 \text { pers. }\end{array}$ & $\begin{array}{l}16.9 \% \\
5 \text { pers. }\end{array}$ & & & 7 \\
\hline Germany & 515 & 500 & $x$ & & $x$ & 12 & $\begin{array}{c}442 \mathrm{mg} \text { (up to } \\
1000 \mathrm{mg} \text { per day) }\end{array}$ & $99 \mathrm{mg}$ & $\begin{array}{l}67 \% \\
350 \text { pers }\end{array}$ & $\begin{array}{l}40 \% \\
200 \\
\text { pers }\end{array}$ & $\begin{array}{l}31 \% \\
108 \text { pers. }\end{array}$ & $\begin{array}{l}45 \% \\
90 \text { pers. }\end{array}$ & $\begin{array}{c}80 \% \\
280 \text { pers. }\end{array}$ & $\begin{array}{c}74 \% \\
148 \text { pers. }\end{array}$ & 177 \\
\hline Canada & 115 & 111 & $x$ & & $x$ & 12 & $\begin{array}{c}392 \mathrm{mg} \text { (max } \\
1000 \mathrm{mg} \text { per day) }\end{array}$ & $96 \mathrm{mg}$ & $\begin{array}{l}88 \% \\
101 \text { pers }\end{array}$ & $\begin{array}{l}54 \% \\
60 \text { pers. }\end{array}$ & \begin{tabular}{|l}
$33 \%$ \\
33 pers.
\end{tabular} & $\begin{array}{c}52 \% \\
31 \text { pers. }\end{array}$ & & & 51 \\
\hline UK & 43 & 42 & $x$ & & $x$ & 6 & $399 \mathrm{mg}$ & $107 \mathrm{mg}$ & $\begin{array}{l}88 \% \\
38 \text { pers }\end{array}$ & $\begin{array}{l}69 \% \\
29 \text { pers. }\end{array}$ & $34 \%$ & $81 \%$ & & & 7 \\
\hline
\end{tabular}

*Outcomes were assessed — using a composite score of measures based on ASI (Addiction Severity Index; McLellan et al., 1992), OTI (Opiate Treatment Index; Darke et al., 1992), SCL90 (Symptom Checklist-90; Derogatis and Cleary, 1997) and SF-12 (Short Form-12; Gandek et al., 1998).

Source: Switzerland trial (Perneger et al., 1998), Netherlands trial (Van den Brink et al., 2003), Spain trial (March et al., 2006), Germany trial (Haasen et al., 2007), Canada trial (Oviedo-Joekes et al., 2009), UK trial ( Strang et al., 2010)

of intoxication with narcotics, achieving formal abstinence (considering that they used heroin as drug treatment), prevention of criminal activity (which is expected when there is no need to find ways of ensuring dose of „street" heroin, when heroin is available, free of charge and more over in the form of injection). Objectives of the studies were also to stabilize the addicted person and to reduce the harm.

The studies assess the efficacy of the prescribed intravenous diacetylmorphine versus oral methadone with medical and psychosocial support, with view of improving physical and mental health as well as social integration among socially excluded, opioid dependant individuals for whom standard treatments have failed [21]. The studies assess also retention in treatment, illicit drug use, HIV risk behavior, criminal activity, social functioning, health and psychological status as measured by self-report, urinalysis and doctor's ratings [19].

In most of the trials for evaluation of the treatment of persons addicted to drugs, as a medication is used heroin that enters the body by injection, and in addition, treatment with flexible dosage of methadone, but in oral dosage form. These patients are monitored during the study, and as a control (comparison group) were persons to whom were administered only oral form of methadone, without combining it with heroin $[18,20,21,51]$.

A study conducted in Switzerland analyzed and compared the effect of heroin, among persons with developed drug addiction. Heroin was in form of injection. Comparison group were persons selected from the waiting lists for treatment and they used treatment option of their choice, available at that time in Geneva [54].

In the study conducted in the Netherlands, persons with addiction were treated with heroin, but in dosage form: inhalation, complemented with methadone in oral form [20]. As a comparison group of patients were patients to which methadone was given in oral form.

Questionnaires, interviews, and medical examinations done at entry point to assess somatic and 
mental health, social integration, and treatment outcomes were used in the trials [22]. Measure of patient response was a reduction in illicit drug use or criminal activity as based on the composite score of the European Addiction Severity Index (EUROP-ASI). Outcomes were assessed at stages in the trial - at baseline and follow-up months with using a complex score of measures of general health, self-reported 'street' heroin use, quality of life, drug addiction-related problems, risk behavior for HIV and hepatitis $\mathrm{C}$ virus, psychological functioning, and social and family status as based on ASI (Addiction Severity Index) [47], OTI (Opiate Treatment Index) [48], SCL-90 (Symptom Checklist-90) [49] and SF-12 (Short Form-12) [50].

The primary outcome measures in the trial included a reduction of self-reported drug use, reduction of 'street' heroin use and improved health status and social functioning.

Secondary outcomes across trials included, but were not limited to, safety, criminal activity, other drug use, physical health, and psychological and social functioning. Also the cost-effectiveness was assessed [39].

A measure of reduction of 'street' heroin and/or other drug use, rather than abstinence, was consistently used across the trials. For example main aim of two open-label randomized controlled trials in the Netherlands were to investigate patient characteristics to medical heroin prescription compared to standard methadone maintenance treatment. Analysis showed that treatment with medically prescribed heroin plus methadone was significantly more effective (51.8\% response) than standard methadone maintenance treatment (28.7\%) Multivariate logistic regression analyses showed that only one of all baseline characteristics was predictive of a differential treatment effect: patients who had previously participated in abstinence-orientated treatment responded significantly better to heroin-assisted treatment than to methadone treatment $(61 \%$ versus $24 \%$ ), while patients without experience in abstinenceorientated treatment did equally well in heroin-assisted or methadone maintenance treatment (39\% and 38\%, respectively) [41].

Randomized controlled trial comparing injected diacetylmorphine and oral methadone was carried out in Andalusia, Spain. The subsequent follow-up study evaluated the health and drug use status of participants, 2 years after the completion of the trial. Data collected included information on socio-demographics, drug use, health and health-related quality of life. Compared data collected before randomization and at 2 years for the following three groups: those currently on heroin-assisted treatment, those who have discontinued .Patients who received on heroin-assisted treatment showed better outcomes compared with those not on heroin-assisted treatments. The results of this study strengthen the evidence showing that on heroin-assisted treatment can improve and stabilize the health of long-term heroin users with severe co morbidities and high mortality [42].

Observational cohort study to describe 4-year treatment retention and treatment response among chronic, treatment-resistant heroin-dependent patients offered long-term heroin-assisted treatment in the Netherlands, showed four-year retention 55.7\% [95\% confidence interval (Cl): 47.6-63.8\%]. It was concluded that long-term heroin-assisted treatments is an effective treatment for chronic heroin addicts who have failed to benefit from methadone maintenance treatment. Four years of heroin-assisted treatments is associated with stable physical, mental and social health and with absence of illicit heroin use and substantial reductions in cocaine use [43].

Functioning across several life domains, crosssectional study with a 6-month follow-up assessed that the Heroin Prescribed group manifested lower levels of psychopathology and showed greater retention in treatment. Although reduced, illicit heroin misuse was not eliminated; the use of other illicit substances was comparable between groups but significantly more of the Heroin Prescribed groups were using illicit cocaine. No differences in current physical health were apparent, criminal activity appeared significantly reduced, but not eliminated, in the Heroin Prescribed group [23].

All these findings support the hypothesis that under the supervised conditions heroin could be safely delivered. In physical health, HIV risk behavior, street heroin use, and days involved in crime, heroin used as a medicine plus methadone was more efficacious than methadone alone [21].

Some argument contra the thesis is that of the estimated 270000 heroin addicts in the UK, only about $300-400$ people are prescribed heroin for their addiction, despite the fact that a subset of people (about 5-10\% of all heroin addicts) do not respond to methadone treatment, take methadone but continue to use heroin illegally, and refuse to try existing treatments that might be of benefit. Some experts are skeptical about whether these clinics are really the way forward [44]. 
This paper review also aims to look at dose of heroin. Research studies in Europe report that the therapeutic dosage of heroin is usually $400-600 \mathrm{mg} / \mathrm{day}$ [30]. Researches from Netherlands notify that in heroin maintenance therapy high doses pharmaceutically prepared heroin (up to $1000 \mathrm{mg} /$ day) are prescribed to chronic heroin dependents, who do not respond to conventional interventions such as methadone maintenance treatment [31]. In the Swiss study patients were stabilized on 500 to 600 .mg heroin daily [32]. As correlation Methadone maintenance doses is in the range of $60-120 \mathrm{mg}$ per day [5].

As an extremely important segment in terms of assessing the degree of harmfulness of each drug and/ or substance that could potentially be used in pharmacological treatment is certainly proper metabolism active component. As an illustration, while Methadone is metabolized primarily in the liver [38], kidneys are primarily involved in the excretion of morphine and morphine glucuronides following heroin administration[33-34] Liver enzymes are involved in heroin hydrolysis and glucuronidation of the heroin metabolite morphine. The liver is the major organ involved in the glucuronidation of morphine [31]. Morphine-3-gluronide (M3G) is the major metabolite (M6G/ M3G ratio approximately 0.15) [35]. Morphine-glucuronides are hydrophylic compounds, that are mainly excreted in urine, and in minor quantities in bile.

In order to analyze the situation from all aspects it is useful to mention the existence of heroin injecting centers which are supervised. Medically supervised injecting centers are "legally sanctioned and supervised facilities designed to reduce the health and public order problems associated with illegal injection drug use." Their purpose is to enable the consumption of preobtained drugs under hygienic, low risk conditions [56]. Worldwide, medically supervised injecting centers (also referred to as health rooms, supervised injecting rooms, drug consumption rooms, and safer injecting rooms or facilities) were opened in Sydney, Australia, Germany [58] in the Netherlands, in Switzerland and Spain [59]. They are open from morning to late evening to accommodate drug users who inject up to three times a day [40].

The United Nations International Narcotics Control Board views the centers as violating international drug conventions [60].

\section{Discussion}

The main objective of the conducted studies is to define treatment maintenance of adult chronic drug addicts in order to eliminate the use of illegal drugs, "street drugs" and risky behavior in terms of criminal activities to provide the drug, the occurrence of possible blood-transmitted diseases and functioning within the family and society as a whole. Also these studies aimed to verify the effectiveness, safety of maintenance treatment, retention of the patient into treatment, to define the daily dose of substitution therapy and with counseling therapy to reduce as much as possible, the degree of parallel use of other substances, alcohol, benzodiazepines etc. Regarding the first group of targets of the studies, it can be concluded that there has been a significant step forward. Mainly all studies confirmed the following benefits of the treatment: reducing of illegal drug use [24], avoiding illness and death as a result of overdose by ensuring access to a drug of known quality and strength [25], retention in medical care [25] reducing the risk of HIV and hepatitis follow-on unsafe injection practices [26], reducing crime related to drugs, promoting social integration, including employment, accommodation and family life [27].

What is perceived is that all performed studies do not used heroin as a treatment of addiction in the same category. There are substantial differences in methodology. Namely, some studies have used heroin in the form of an injection alone, sometimes in combination therapy with methadone who is in oral form and diluted, in other studies heroin and methadone are applied in the form of injection, while in some studies, (the Netherlands) heroin in the form of inhalation. The method of application is extremely important in the context of its pharmacokinetics and pharmacodynamics, and consequently to the effect achieved. This different methodology further puts into question the results especially in the context of the small (limited) total number of persons in the studies to whom heroin as a treatment was applied. As a parallel: The average prevalence of problem opioid use in the European Union and Norway is estimated to be between 3.6 and 4.4 cases per 1000 population aged 15-64. This corresponds to some 1.35 million (1.2-1.5 million) problem opioid users in the EU and Norway in 2008 [28].

Methadone is usually administered orally and as such is rapidly absorbed, diacetylmorphine (heroin) is usually administered intravenously. In the trials heroin was supervised but self-administrated [39]. Two issues should be taken into consideration: what in cases and 
that is not uncommon among drug addicts, when person has a collapse of the veins, sclerosis and/or thrombosis of the veins? If treatment takes place in specialized institutions and under the supervision of medical staff, including nurses, why in the studies as a main option is self administration of intravenous heroin?

Medically supervised injecting centers was set up, open from morning to late evening to accommodate drug users who inject up to three times a day[40]. All efforts of the new therapies are patient to return to "normal" way of life and integrate into society. Is it rational such a patient to come to medical facility 3 times a day for therapy, including time about 30 mins, after each administration of heroin needed for observation of the patient? As well, there are additional financial costs of transport 3 times a day. Is this arrangements will be attractive enough for the patient to retain on the treatment from one side and from the the other, how he can efficiently perform normal work activities during the day.

Lastly but not least, whether such therapy will be keep only for groups that do not respond to other kind of therapy. Availability of heroin in the form of injection can be attractive to other drug addicts, as well. Consequently, there is a risk of possible increase in the number of heroin addicts, if and when pharmaceutical preparations of heroin will have a marketing authorization.

Considering the higher rate of serious adverse events, the eventual risk-benefit balance of heroin prescription should be carefully evaluated before its implementation in clinical practice [55].

In conclusion, main aim of something new is to get more, to get closer to the goal. The main goal of therapy is abstinence. New forms of therapy with heroin, rapidly increase the treatment dose of opioids. But considering that there are a limited number of subjects, different and combined approach, may be it should be noted that the evidence database of records is relatively weak and it is necessary to perform further tests, taking into account more of the medical aspects of the action of the new therapy, no just improvement of social performance and to set up conclusion whether the introduction of heroin as a treatment, reduce harm from drug use, or increase it.

From human aspect, new treatment will protect patients from criminal activities, but will it contribute to improvement of health as well or not?

\section{Acknowledgements}

Publication fee for this review article was covered by Ss Cyril and Methodius University Skopje PhD School.

\section{References}

1. Joint UNODC-WHO Action Programme On Drug Dependence Treatment Scaling Up Evidence-Based Services For Drug Dependence Treatment And Care for 2009-2013, 2008.

2. Afuwape SA. Where are we with dual diagnosis (substance misuse and mental illness)?

3. A review of the literature, November, 2003, Rethink and Turning Point, www.rethink.org/dualdiagnosis.

4. www.drugabuse.gov.

5. Ward J, Bell J, Mattick RP. Methadone maintenance therapy for opioid dependence: A guide to appropriate use. CNS Drugs. 1996;6(6):440-9.

6. Guidelines for the Psychosocially Assisted Pharmacological Treatment of Opioid Dependence World Health Organization 2009

7. Dole VP, Robinson JW, Orraca J, Towns E, Searcy P, Caine E. Methadone treatment of randomly selected criminal addicts. The New England journal of medicine. 1969;280(25):1372-5.

8. Gowing LR, Farrell M, Bornemann R, Sullivan LE, Ali RL. Brief report: Methadone treatment of injecting opioid users for prevention of HIV infection. J Gen Intern Med. 2006;21(2):1935.

9. Gronbladh L, Ohlund LS, Gunne LM. Mortality in heroin addiction: impact of methadone treatment. Acta psychiatrica Scandinavica. 1990;82(3):223-7.

10. Newman RG, Whitehill WB. Double-blind comparison of methadone and placebo maintenance treatments of narcotic addicts in Hong Kong. Lancet. 1979;2(8141):485-8.

11. Lenne M, Lintzeris N, Breen C, Harris S, Hawken L, Mattick $\mathrm{R}$, et al. Withdrawal from methadone maintenance treatment: prognosis and participant perspectives. Australian and New Zealand journal of public health. 2001;25(2):121-5.

12. UN Convention for narcotic drugs 1961, UN Convention for psychotropic substances 1972, UN Convention against illicit production and trafficking with narcotics, 1988.

13. UNODC (2011). World Drug Report. UNITED NATIONS OFFICE ON DRUGS AND CRIME.

14. UNODC World Drug Report, 2009.

15. Journal of epidemiology \& community health http:// 
jech.bmj.com/content/58/9/747.full

16. Teesson M, Ross J, Darke S, Lynskey M, Ali R, Ritter A and Cooke R. One year outcomes for heroin dependence: findings from the Australian Treatment Outcome Study (ATOS). Drug \& Alcohol Dependence 2006;83(2):174-180.

17. Hser YI, Anglin MD and Fletcher B. Comparative treatment effectiveness. Effects of program modality and client drug dependence history on drug use reduction. Journal of Substance Abuse Treatment. 1998;15(6):513-523.

18. Strang J, Groshkova T, Metrebian N. Emcdda insights. New heroin-assisted treatment, Recent evidence and current practices of supervised injectable heroin treatment in Europe and beyond, 2012.

19. Metrebian N, Shanahan W, Wells B, Stimson GV Department of Social Science and Medicine, Imperial College School of Medicine, London, United Kingdom, Feasibility of prescribing injectable heroin and methadone to opiatedependent drug users: associated health gains and harm reductions. Med J Aust. 1998;168(12):596-600.

20. van den Brink W, Hendricks VM, Blanken P et al. (2003), 'Medical prescription of heroin to treatment resistant heroin addicts: two randomised trials', British Medical Journal. 2003; 327:310-316.

21. March JC, Oviedo-Joekes E,Perea-Milla E, Carrasco F, Andalusian School of Public Health,Granada 18080, Spain Controlled trial of prescribed heroin in the treatment of opioid addiction, J Subst Abuse Treat. 2006:31(2)203-11.

22. Rehm J, Gschwend P, Steffen T, Gutzwiller F, Dobler-Mikola A, Uchtenhagen A. Addiction Research Institute, Zurich, Switzerland Feasibility, safety, and efficacy of injectable heroin prescription for refractory opioid addicts: a follow-up study. Lancet. 2000;359(9309):889-90.

23. McCusker C, Davies M. Department of Clinical Psychology, School of Psychology, Queen's University of Belfast, Northern Ireland. Prescribing drug of choice to illicit heroin users: the experience of a U.K. community drug team.

24. Kerr T, Montaner JS, Wood E. Science and politics of heroin prescription. Lancet. 2010;375(9729):1849-50.

25. Naber D, Haasen C. Centre for Interdisciplinary Addiction Research of Hamburg University. The German Model Project for Heroin Assisted Treatment of Opioid Dependent Patients - A Multi-Centre, Randomised, Controlled Treatment Study: Clinical Study Report of the First Study Phase, January 2006.

26. Strang et al. Supervised injectable heroin or injectable methadone versus optimised oral methadone as treatment for chronic heroin addicts in England after persistent failure in orthodox treatment (RIOTT): a randomised trial. Lancet. 2010;375(9729).

27. Csete J. From the Mountaintops: What the World Can Learn from Drug Policy Change in Switzerland. Global Drug Policy Program (New York, NY: Open Society Foundations, May 2010).

28. EMCCDA. Annual Report 2010. http:// www.emcdda.europa.eu/events/2010/annual-report.

29. Farrell M. National Addiction Centre, Institute of Psychiatry, London SE5 8AF Wayne Hall. The Swiss heroin trials: testing alternative approaches BMJ. 1998;316(7132): 639.

30. Carnwath T, Merrill J. Dose equivalents in opioid substitution treatment. International Journal of Drug Policy. 2002;13:445447.

31. Rook EJ, Huitema AD, van den Brink W, van Ree JM, Beijnen $\mathrm{JH}$. Pharmacokinetics and pharmacokinetic variability of heroin and its metabolites: review of the literature. Curr Clin Pharmacol. 2006;1(1):109-18.

32. Farrell M, Hall W. The Swiss heroin trials: testing alternative approaches. BMJ. 1998;316(7132):639.

33. Mo BP, Way EL. An assessment of inhalation as a mode of administration of heroin by addicts. J Pharmacol Exp Ther. 1966;154:142-51.

34. Elliott HW, Parker KD, Wright JA, Nomof N. Actions and metabolism of heroin administered by continuous intravenousinfusion to man. Clin Pharmacol Ther. 1971;12: 806-14.

35. Faura CC, Collins SL, Moore RA, McQuay HJ. Systematic review of factors affecting the ratios of morphine and its major metabolites. Pain. 1998; 74: 43-53.

36. Mo BP, Way EL. An assessment of inhalation as a mode of administration of heroin by addicts. JPharmacol Exp Ther. 1966;154:142-51.

37. Elliott HW, Parker KD, Wright JA, Nomof N. Actions and metabolism of heroin administered by continuous intravenous infusion to man. Clin Pharmacol Ther. 1971;12:806-14.

38. Kreek MJ, Schecter AJ, Gutjahr CL, Hecht M. Methadone use in patients with chronic renal disease. Drug Alcohol Depend. 1980;5(3):197-205.

39. van den Brink W, Hendriks VM, Blanken P, Huijsman IA, van Ree JM. Medical co-prescription of heroin two randomized controlled trials. Central Committee on the Treatment of Heroin Addicts (CCBH) Utrecht, The Netherlands, 2002.

40. Wright NM, Tompkins CN. Supervised injecting centres. BMJ. 2004;328(7431):100-2.

41. Blanken P, Hendriks VM, Koeter MW, van Ree JM, van den Brink W. Matching of treatment-resistant heroin-dependent patients to medical prescription of heroin or oral methadone treatment: results from two randomized controlled trials, Cochrane Database Syst Rev. 2003;(4):CD003410. 
42. Oviedo-Joekes E, March JC, Romero M, Perea-Milla E. The Andalusian trial on heroin-assisted treatment: a 2 year follow-up. Drug Alcohol Rev. 2010;29(1):75-80.

43. Blanken P, Hendriks VM, van Ree JM, van den Brink W. Central Committee on the Treatment of Heroin Addicts, University Medical Centre Utrecht, Utrecht, The Netherlands. Outcome of long-term heroin-assisted treatment offered to chronic, treatment-resistant heroin addicts in the Netherlands, 2010.

44. Shetty P. UK Government considers supervised injecting clinics. Lancet. 2008;371(9612):545-6.

45. National Institute on Drug Abuse. Principles of Drug Addiction Treatment: A Research-Based Guide (Second Edition). NIH Pub Number: 09-4180 Revised: April 2009.

46. McLellan AT, Lewis DC, O'Brien CP, Kleber HD. Drug dependence, a chronic medical illness: implications for treatment, insurance, and outcomes evaluation. JAMA. 2000;284(13):1689-95.

47. Carise D, McLellan AT, Cacciola J, Love M, Cook T, Bovasso G, Lam V. Suggested specifications for a standardized Addiction Severity Index database. J Subst Abuse Treat. 2001;20(3):239-44.

48. Darke S, Hall W, Wodak A, Heather N, Ward J. Development and validation of a multi-dimensional instrument for assessing outcome of treatment among opiate users: the Opiate Treatment Index. Br J Addict. 1992;87(5):733-42.

49. Kirchmann H, Schreiber-Willnow K, Seidler KP, Strauss B. SCL-90-R symptom profile clusters among inpatients undergoing psychodynamic group psychotherapy: cluster stability, associations with clinical characteristics and treatment outcome. Psychopathology. 2011;44(2):71-82.

50. Gandek B, Ware JE, Aaronson NK, Apolone G, Bjorner JB, Brazier JE, Bullinger M, Kaasa S, Leplege A, Prieto L, Sullivan M. Cross-validation of Item Selection and Scoring for the SF-12 Health Survey in Nine Countries: Results from the IQOLA Project. J Clin Epidemiology. 1998;51(11):1171-8.
51. Haasen C, Verthein U, Degkwitz P, Berger J, Krausz M, Naber D. Heroin-assisted treatment for opioid dependence: randomised controlled trial. Br J Psychiatry. 2007;191:55-62.

52. Gerstein DR, Harwood HJ. Evaluating recovery services: The California drug and alcohol treatment system (CALDATA): General report. Sacromento: Californai Department of Alcohol and Drug Programs, 1994.

53. Gossop M, Stewart D, Marsden J. Effectiveness of drug and alcohol counseling during methadone treatment: content, frequency, and duration of counseling and association with substance use outcomes. Addiction. 2006;101:404-412.

54. Perneger TV, Giner F, del Rio M, Mino A. Randomised trial of heroin maintenance programme for addicts who fail in conventional drug treatments. BMJ. 1998;317(7150):13-8.

55. Ferri M, Davoli M, Perucci CA. Heroin maintenance for chronic heroin-dependent individuals. Cochrane Database Syst Rev. 2011 Dec 7;(12):CD003410.

56. Consumption Rooms as a Professional Service in Addictions Health: International Conference for the development of guidelines. Guidelines for the operation and use of consumption rooms. 1999. www.adf.org.au/ injectingrooms/guidelines.pdf (accessed 11 Nov 2003).

57. Carlson RG. Shooting galleries, dope houses, and injection doctors: examining the social ecology of HIV risk behaviors among drug injectors in Dayton, Ohio. Hum Organ. 2000;59(3): 325.

58. Stoever H. Consumption rooms-a middle ground between health and public order concerns. J Drug Iss. 2002;32:597606.

59. European Monitoring Centre for Drugs and Drug Addiction. Annual report on the state of the drugs problem in the European Union and Norway. Luxembourg: EMCDDA, 2002.

60. Yamey G. UN condemns Australian plans for "safe injecting rooms". BMJ. 2000;320:667. 